\title{
LETTER
}

\section{Non-leukodepleted red blood cell transfusion in sepsis patients: beyond oxygenation, is there a risk of inflammation?}

\author{
Olivier Garraud ${ }^{1,2^{*}}$, Adrien Chabert ${ }^{1}$, Bruno Pozzetto ${ }^{1,3}$, Fabrice Zeni ${ }^{1,4}$, Fabrice Cognasse ${ }^{1,5}$ and Hind Hamzeh-Cognasse
}

See related research by Donati et al., http://ccforum.com/content/18/1/R33

Donati and colleagues [1] evaluated the benefits of fresh, leukodepleted (LD) versus non-leukodepleted (nLD) erythrocyte transfusions on the microcirculation in sepsis patients. Oxygenation appeared equal in both groups. Differences between the two kinds of blood cells are presented in Table 1. In the reported study, there is a difference between the age of erythrocytes in the two groups (1.5 to 3 days for $\mathrm{nLD}$ versus 3.5 to 5 days for LD erythrocytes; a $U$ test indicates $P<0.05$ ); this suffices to influence oxygen delivery mediators (Figure 1). The content of leukocytes prior to (and after) leukodepletion were not tested, nor was the freeing - which is usually very fast - of secreted or docked, soluble biological response modifiers. Considering the dynamics of secreted biological response modifiers in platelet components [2], there must be differences within the two groups, which possibly influenced sepsis conditions. Residual plasma within erythrocytes given by female donors may include antihuman leukocyte antigen (HLA) antibodies which attack the recipient's lung alveolar epithelium neutrophils, and as sepsis is characterized by the pathology of neutrophils that release microparticles and neutrophil extracellular traps that target lung epithelium [3], it may be feared here that the nLD condition aggravates pulmonary lesions.

The re-evaluation of procedures is infrequent in transfusion despite the rapid evolution of techniques and materials; for example, differential stresses are inflicted on erythrocytes, depending on the collection process (aphaeresis versus conventional whole blood), with consequences for neutrophils and (vascular) endothelial cells upon transfusion [4]. Clinical investigations and registered trials such as Donati and colleagues are valuable.

\section{Authors' response}

Abele Donati, Elisa Damiani, Erica Adrario, Rocco Romano, Paolo Pelaia and Can Ince

We thank Professor Garraud and colleagues for their interest in our study [1]. As underlined, the difference in the age of transfused red blood cells (RBCs) between the nLD group (4 (3.5 to 5) days) and the LD group (3 (1.5 to 3) days) may have influenced the RBC oxygen-delivery capacity. Stored RBCs lose their ability to release vasodilators (nitric oxide, ATP) during hypoxia [5,6]. We showed similar changes in microvascular reactivity (tissue oxygen saturation $\left(\mathrm{StO}_{2}\right)$-upslope) and oxygenation $\left(\mathrm{StO}_{2}\right)$ after $\mathrm{nLD}$ or LD RBC transfusions [1]. This may indicate that oxygen-delivery mediators were not sufficiently affected to determine relevant variations in the response observed.

\footnotetext{
*Correspondence: ogarraud@ints.fr

'Université de Lyon, GIMAP-EA3064, Saint Etienne 42023, France

${ }^{2}$ Institut National de Transfusion Sanguine (INTS), Paris 75739, France

Full list of author information is available at the end of the article
}

Alternatively, heterogeneity in the study population prevented detection of subtle differences. Variability in the response to treatments is common during sepsis. The patient heterogeneity was underlined as a limitation of our investigation [1].

LD RBCs showed a more favorable effect on microcirculatory convective flow [1]. This may depend on the lower adhesiveness of LD RBCs to the endothelium [7]. The transfusion of nLD RBCs decreased blood flow velocity and increased glycocalyx damage markers [1]. Similar effects may reasonably occur in the lungs. As highlighted, anti-HLA antibodies in nLD blood from female donors may contribute to aggravate pulmonary lesions. Nonetheless, the evaluation of respiratory function went beyond our goals. 
Table 1 Possible consequences of variation in transfusion conditions and the type of packed red blood cells administered

Variable Primary or immediate consequences (efficacy)

Total volume Possibly needs to be adjusted according to the patient's needs

\section{Hematocrit}

Residual plasma volume

Leukocytes

Age of blood
Possibly needs to be adjusted according to the patient's needs

Possibly includes anti-HLA antibodies (from female donors)

Possibly affects the amount of soluble, free biological response modifiers

No pre-test (possibly affects donor eligibility)

Pre-activation of leukocytes

Release of biological response modifiers

Release of microparticles and neutrophil extracellular

traps

HLA antibody targets

Infectious risk (intracellular viruses)

Decreases the benefit of oxygen transport

Release of microparticles

Expression of stress signals on red blood cells

Free iron release

NO and iNOS release

Oxygenated lipid and lipid degradation Secondary or delayed consequences (hazards)

Possibly needs to be adjusted to correct for anemia

Possibly needs to be adjusted to correct for anemia Increases the risk of TRALI

Increases the risk of inflammation and aggravates the risk of TRALI

Increases the risk of inflammation

Aggravates sepsis

Increases the risk of TRALI

Increases the risk of viral infections

Increases the risk of inflammation

Potentiates the risk of TRALI by stressing target neutrophils

Possibly increases the risk of allo-immunization
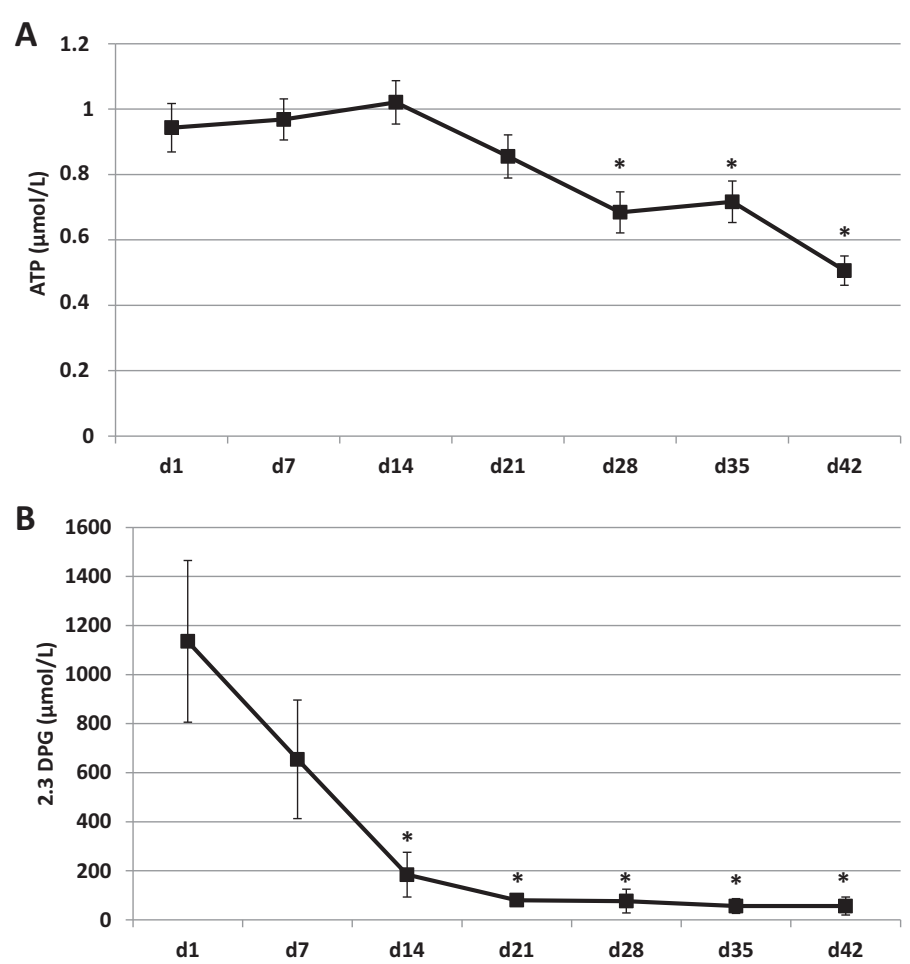

Figure 1 ATP and 2,3-diphosphoglycerate (2.3-DPG) in packed red blood cells. (A) ATP and (B) 2.3-DPG in packed red blood cells measured after 1, 7, 14, 21, 28, 35 and 42 days (d) of storage were re-evaluated by one-way analysis of variance. Inter-experiment differences in ATP and 2.3-DPG concentrations at different time points were analyzed by Wilcoxon paired test (XLSTAT ${ }^{\oplus} 2010$ software, Addinsoft, Paris, France). $P$-values $\leq 0.05$ were considered to be significant $\left({ }^{*} n=10\right)$. PLT, platelet. 
The efficacy of blood transfusion depends on multiple RBC- and patient-related factors. Understanding the response to transfusion during sepsis is a challenging task. Targeting predetermined hemoglobin levels and/or macrohemodynamics is clearly not sufficient. Monitoring the microcirculation may get us closer to the answer [8].

\section{Abbreviations}

HLA: Human leukocyte antigen; LD: Leukodepleted; nLD: Non-leukodepleted; $\mathrm{RBC}$ : Red blood cell; $\mathrm{StO}_{2}$ : Tissue oxygen saturation.

\section{Competing interests}

The authors declare that they have no competing interests.

\section{Author details}

${ }^{1}$ Université de Lyon, GIMAP-EA3064, Saint Etienne 42023, France. ${ }^{2}$ Institut National de Transfusion Sanguine (INTS), Paris 75739, France. ${ }^{3}$ Département de Microbiologie Hôpital Nord, CHU de Saint-Etienne, Saint-Etienne 42055, France. ${ }^{4}$ Service de Réanimation Médicale et Polyvalente Hôpital Nord, CHU de Saint-Etienne, Saint-Etienne 42055, France. ${ }^{5}$ Etablissement Français du Sang Auvergne-Loire, Saint-Etienne 42100, France.

Published online: 08 December 2014

\section{References}

1. Donati A, Damiani E, Luchetti MM, Domizi R, Scorcella C, Carsetti A, Gabbanelli V, Carletti P, Bencivenga R, Vink H, Adrario E, Piagnerelli M, Gabrielli A, Pelaia P, Ince C: Microcirculatory effects of the transfusion of leukodepleted or non-leukodepleted red blood cells in septic patients: a pilot study. Crit Care 2014, 18:R33.

2. Garraud O, Hamzeh-Cognasse H, Pozzetto B, Cavaillon JM, Cognasse F: Bench-to-bedside review: Platelets and active immune functions - new clues for immunopathology? Crit Care 2013, 17:236.

3. Clark SR, Ma AC, Tavener SA, McDonald B, Goodarzi Z, Kelly MM, Patel KD, Chakrabarti S, McAvoy E, Sinclair GD, Keys EM, Allen-Vercoe E, Devinney R, Doig CJ, Green FH, Kubes P: Platelet TLR4 activates neutrophil extracellular traps to ensnare bacteria in septic blood. Nat Med 2007, 13:463-469.

4. Cognasse F, Garraud O, Hamzeh-Cognasse H, Damien P, Nguyen KA, Pozzetto B, Payrat JM: Investigative in vitro study about red blood cell concentrate processing and storage. Am J Respir Crit Care Med 2013, 187:216-217.

5. Van de Watering LMG, Brand A: Effects of storage of red cells. Transfus Med Hemother 2008, 35:359-367.

6. Reynolds JD, Ahearn GS, Angelo M, Zhang J, Cobb F, Stamler JS: S-nitrosohemoglobin deficiency: a mechanism for loss of physiological activity in banked blood. Proc Natl Acad Sci U S A 2007, 104:17058-17062.

7. Anniss AM, Sparrow RL: Storage duration and white blood cell content of red blood cell (RBC) products increases adhesion of stored RBCs to endothelium under flow conditions. Transfusion 2006, 46:1561-1567.

8. Donati A, Domizi R, Damiani E, Adrario E, Pelaia P, Ince C: From macrohemodynamic to the microcirculation. Crit Care Res Pract 2013, 2013:892710. 